\title{
A potential mechanism for extracellular matrix induction of breast cancer cell normality
}

\author{
Robert D Bruno ${ }^{1}$ and Gilbert H Smith ${ }^{2^{*}}$
}

\begin{abstract}
Extracellular matrix proteins from embryonic mesenchyme have a normalizing effect on cancer cells in vitro and slow tumor growth in vivo. This concept is suggestive of a new method for controlling the growth and spread of existing cancer cells in situ and indicates the possibility that extracellular proteins and/or embryonic mesenchymal fibroblasts may represent a fertile subject for study of new anti-cancer treatments.
\end{abstract}

Bischof and colleagues have made a case for breast cancer cell normalization by biglycan isolated from embryonic mesenchyme in vitro [1]. Further, they show that injection of extracellular matrix (ECM) isolated from embryonic mesenchymal fibroblasts grown in vitro can suppress tumor growth when inoculated directly into growing tumors in vivo. Their results shed light on the potential mechanism by which embryonic mesenchyme can control tumorigenic expression of cancer cells, which was demonstrated by several investigators decades ago $[2,3]$. The evidence indicates that only ECM from inductive mesenchyme is effective in normalization of cancer cells. In Bischof and colleagues' report, cancerassociated fibroblasts failed to produce a normalizing effect. The authors went on to show that tenascin $\mathrm{C}$ and biglycan were two ECM proteins that were uniquely expressed by inductive embryonic mesenchymal fibroblasts. Further, they demonstrated that only biglycan was able to normalize cancer cells in vitro. Isolated growth factors associated tightly with the purified ECM were ineffective in normalizing breast cancer cells. Finally, siRNA knockdown of biglycan mRNA and protein in embryonic fibroblasts abrogated their ability to normalize breast cancer cells or reduce their growth in vitro.

\footnotetext{
* Correspondence: smithg@mail.nih.gov

${ }^{2}$ Mammary Stem Cell Biology Section, CCBB, Center for Cancer Research, NCl, Bethesda, MD 20892, USA

Full list of author information is available at the end of the article
}

Biglycan has been disrupted by targeting in mice, and variously leads to an osteoporosis-like phenotype and biomechanically affected specific tendons [4-6]. One wonders how the embryonic mesenchyme from these models might behave in normalization studies.

While the implication of a single ECM component, biglycan, is intriguing from a therapeutic perspective, this reductionist view of the role of ECM in controlling tumorigenesis is not in agreement with the published literature. Schedin and colleagues have very carefully studied the role of mammary ECM in breast tumorigenesis [7-10]. They have found that reproductive history and the developmental state of the gland from which the breast ECM was isolated alters the effects of the ECM on tumor growth. For instance, ECM derived from involuting mammary tissues has pro-tumor effects compared with that isolated from nulliparous tissues, and this protumorigenic potential is thwarted by treatment with nonsteroidal anti-inflammatory drugs [8,9]. In addition, they report that ECM isolated from parous mammary glands has an inhibitory effect on tumor growth [7]. Contrary to Bischof and colleagues' findings that biglycan is uniquely expressed in inductive mesenchyme, biglycan was found to be present in ECM preparations from nulliparous, parous, and involuting (with or without prior nonsteroidal anti-inflammatory drug treatment) rat mammary glands. Further, no significant differences in biglycan concentrations were identified between these ECM preparations $[7,10]$.

Our laboratory has also been interested in trying to understand tissue-microenvironment-induced suppression of cancer cell tumorigenesis. Our data demonstrate that pluripotent human male cancer cells, mouse embryonic stem cells and breast cancer cells from both mouse and human can be induced to differentiate and not produce tumors in the mouse mammary gland during regenerative growth [11-14]. All of our published data have been determined in postpubertal mammary fat pads whose mesenchyme, according to Sakakura and colleagues [15], had lost inductive activity after interaction 
with mammary epithelium in utero at day 17. Thus, our observations and those of Schedin and colleagues do not agree with the conclusion of Bischof and colleagues that biglycan is sufficient for tumor cell normalization and that tumor cell normalization is unique to inductive mesenchyme.

The specific components involved in tumor-cell normalization are likely to be context dependent. Furthermore, changes in ECM architecture rather than ECM composition are implicated in tumor suppression by ECM isolated from mammary glands of parous rats [7], adding an additional layer of complexity to the story. Therefore, reductionist approaches to understanding these issues should be cautioned. What is clear from the whole of the published literature, including the recent report by Bischof and colleagues, is the indispensable role of the local microenvironment, including the ECM, in controlling cell growth, survival, and fate determination.

\section{Abbreviations}

ECM: Extracellular matrix; siRNA: Small interfering RNA.

\section{Competing interests}

The authors declare that they have no competing interests.

\section{Author details}

${ }^{1}$ School of Medical Diagnostic and Translational Sciences, College of Health Sciences, Old Dominion University, Norfolk, VA 23529, USA. ${ }^{2}$ Mammary Stem Cell Biology Section, CCBB, Center for Cancer Research, NCl, Bethesda, MD 20892, USA.

\section{Published: 17 Feb 2014}

\section{References}

1. Bischof AG, Yuksel D, Mammoto T, Mammoto A, Krause S, Ingber DE: Breast cancer normalization induced by embryonic mesenchyme is mediated by extracellular matrix biglycan. Integr Biol (Camb) 2013, 5:1045-1056.

2. Parchment RE, Gramzinski RA, Pierce GB: Embryonic mechanisms for abrogating the malignancy of cancer cells. Prog Clin Biol Res 1990, 354A:331-344

3. Pierce GB, Arechaga J, Wells RS: Embryonic control of cancer. Prog Clin Biol Res 1986, 226:67-77.

4. Xu T, Bianco P, Fisher LW, Longenecker G, Smith E, Goldstein S, Bonadio J, Boskey A, Heegaard AM, Sommer B, Satomura K, Dominguez P, Zhao C, Kulkarni $A B$, Robey $P G$, Young MF: Targeted disruption of the biglycan gene leads to an osteoporosis-like phenotype in mice. Nat Genet 1998, 20:78-82.

5. Young MF, Bi Y, Ameye L, Chen XD: Biglycan knockout mice: new models for musculoskeletal diseases. Glycoconj J 2002, 19:257-262.

6. Robinson PS, Huang TF, Kazam E, lozzo RV, Birk DE, Soslowsky LJ: Influence of decorin and biglycan on mechanical properties of multiple tendons in knockout mice. J Biomech Eng 2005, 127:181-185.

7. Maller O, Hansen KC, Lyons TR, Acerbi I, Weaver VM, Prekeris R, Tan AC, Schedin P: Collagen architecture in pregnancy-induced protection from breast cancer. J Cell Sci 2013, 126:4108-4110.

8. MCDaniel SM, Rumer KK, Biroc SL, Metz RP, Singh M, Porter W, Schedin P: Remodeling of the mammary microenvironment after lactation promotes breast tumor cell metastasis. Am J Pathol 2006, 168:608-620

9. O'Brien J, Hansen K, Barkan D, Green J, Schedin P, O'Brien J, Hansen K, Barkan D, Green J, Schedin P: Non-steroidal anti-inflammatory drugs target the pro-tumorigenic extracellular matrix of the postpartum mammary gland. Int J Dev Biol 2011, 55:745-755.

10. O'Brien JH, Vanderlinden LA, Schedin PJ, Hansen KC: Rat mammary extracellular matrix composition and response to ibuprofen treatment during postpartum involution by differential GeLC-MS/MS analysis. J Proteome Res 2012, 11:4894-4905.
11. Booth B, Boulanger C, Anderson L, Smith G: The mammary microenvironment restricts the tumorigenic phenotype of MMTV-neu-transformed tumor cells. Oncogene 2011, 30:679-689.

12. Boulanger CA, Bruno RD, Mack DL, Gonzales M, Castro NP, Salomon DS, Smith GH: Embryonic stem cells are redirected to non-tumorigenic epithelial cell fate by interaction with the mammary microenvironment. PLoS One 2013, 8:e62019.

13. Bussard KM, Boulanger CA, Booth BW, Bruno RD, Smith GH: Reprogramming human cancer cells in the mouse mammary gland. Cancer Res 2010, 70:6336-6343.

14. Bussard KM, Smith GH: Human breast cancer cells are redirected to mammary epithelial cells upon interaction with the regenerating mammary gland microenvironment in-vivo. PLoS One 2012, 7:e49221.

15. Sakakura T, Suzuki Y, Shiurba R: Mammary stroma in development and carcinogenesis. J Mammary Gland Biol Neoplasia 2013, 18:189-197.

$10.1186 /$ bcr3617

Cite this article as: Bruno and Smith: A potential mechanism for extracellular matrix induction of breast cancer cell normality. Breast Cancer Research 2014, 16:302 